\title{
DANO MORAL COLETIVO DECORRENTE DE INFRAÇÃO AMIBIENTAL
}

\author{
André Dias Fernandes \\ Mestre em Direito (UFC). MBA em Poder Judiciário \\ (FGV-Direito-Rio). Professor da FA7. Juiz Federal no Ceará. \\ andredias@jfce.jus.br
}

Sumário: Introdução. 1. Esclarecimentos terminológicos. 2. Dano moral coletivo em matéria ambiental. Conclusão. Referências.

\begin{abstract}
Resumo: Há uma conscientização crescente de que o meio ambiente deve ser protegido da forma mais ampla possível: o aquecimento global, por exemplo, é uma realidade cada vez mais difícil de ser ignorada. Um dos meios mais eficazes para coibir danos ambientais é a condenação judicial por dano moral coletivo. Todavia, embora a existência de dano moral coletivo seja amplamente aceita na doutrina e na jurisprudência dos tribunais regionais federais, um entendimento mais restritivo do STJ, atualmente predominante naquela Corte, tem negado a própria possibilidade de dano moral coletivo, à consideração de que este seria incompatível com a ideia de dor psíquica, com a indeterminabilidade da vítima e com a indivisibilidade da ofensa e da reparação. Contrariamente, neste artigo sustenta-se a perfeita compatibilidade lógico-jurídica do instituto do dano moral coletivo com a ordem jurídica brasileira em vigor.
\end{abstract}

Palavras-chave: Dano moral coletivo. Danos ambientais. Direitos transindividuais. Ações coletivas.

\section{INTRODUÇÃO}

O meio ambiente está na ordem do dia.

A redução da camada de ozônio, causadora do efeito estufa, o desmatamento da Amazônia, a desertificação, a emissão de poluentes atmosféricos, fluviais e marítimos, a busca de outras matrizes energéticas menos poluentes e outros velhos problemas ambientais foram subitamente levados a sério em razão dos catastróficos prognósticos sobre o aquecimento global.

$\mathrm{ACF} / 88$, promulgada há mais de vinte anos, foi pródiga em normas protetivas do meio ambiente.

Todavia, a repentina conscientização mundial acerca da iminência e da extensão dos prováveis efeitos do aquecimento global emprestaram um novo significado ao dever previsto no art. 225 da CF/88: "Art. 225. Todos têm direito 
ao meio ambiente ecologicamente equilibrado, bem de uso comum do povo e essencial à sadia qualidade de vida, impondo-se ao poder público e à coletividade o dever de defendê-lo e preservá-lo para as presentes e futuras gerações."

Assim, diante da necessidade cada vez mais premente de proteger e preservar o meio ambiente "para as presentes e futuras gerações", redescobrem-se e adaptam-se institutos jurídicos em ordem a viabilizá-lo.

Nesse contexto, a figura do dano moral coletivo pode desempenhar um papel de grande relevo na defesa do meio ambiente.

Apesar da ampla aceitação doutrinária, há certa resistência na jurisprudência, designadamente no âmbito do STJ, ao reconhecimento da própria existência jurídica do dano moral coletivo, bem como de sua incidência em matéria ambiental.

Cumpre, pois, analisar os fundamentos jurídicos invocados contra a teoria do dano moral coletivo para verificar se são suficientes para obstar o emprego deste eficaz meio de defesa dos bens ambientais.

\section{ESCLARECIMENTOS TERMINOLÓGICO}

Impende esclarecer, de logo, que a expressão "dano moral coletivo" abrange os direitos coletivos lato sensu, ou seja, compreende não apenas os direitos coletivos stricto sensu, mas também os direitos difusos, de que são exemplo os direitos relativos ao meio ambiente. Com esta significação ampla a locução será utilizada neste texto.

Alguns doutrinadores sustentam ainda que a expressão "dano moral coletivo" compreenderia também quaisquer danos a direitos extrapatrimoniais (direito ao sossego, à saúde etc.), ainda que desprovidos de natureza moral, motivo pelo qual seria mais adequada a locução "dano extrapatrimonial coletivo".

Conquanto seja desejável, de lege ferenda, a criação da figura do "dano extrapatrimonial coletivo", a nosso viso, de lege lata, quando a legislação alude à responsabilização por danos morais coletivos, sua intenção é reportar-se apenas aos prejuízos de ordem moral à coletividade. 


\section{Dano Moral Coletivo em Matéria Ambiental}

Os Tribunais Regionais Federais, de modo geral, admitem a existência de dano moral coletivo, incluidamente em matéria ambiental, havendo várias condenações a esse título ${ }^{1}$.

Todavia, no julgamento do REsp 598.281/MG, decidiu o STJ que não há falar em dano moral coletivo, porquanto o dano moral (a) é indissociável dos sentimentos de dor, aflição, angústia psíquica e (b) é incompatível com a indeterminação das vítimas, e com a indivisibilidade da ofensa e da reparação. Confira-se a ementa do aresto em tela:

PROCESSUAL CIVIL. AÇÃO CIVIL PÚBLICA. DANO AMBIENTAL. DANO MORAL COLETIVO. NECESSÁRIA VINCULAÇÃO DO DANO MORAL À NOÇÃO DE DOR, DE SOFRIMENTO PSÍQUICO, DE CARÁTER INDIVIDUAL. INCOMPATIBILIDADE COM A NOÇÃO DE TRANSINDIVIDUALIDADE (INDETERMINABILIDADE DO SUJEITO PASSIVO E INDIVISIBILIDADE DA OFENSA E DA REPARAÇÃO). RECURSO ESPECIAL IMPROVIDO.

(REsp 598281/MG, Rel. Ministro LUIZ FUX, Rel. p/ Acórdão Ministro TEORI ALBINO ZAVASCKI, PRIMEIRA TURMA, julgado em 02/05/2006, DJ 01/06/2006, p. 147)

\footnotetext{
Eis dois exemplos: "DIREITO AMBIENTAL E PROCESSUAL CIVIL. AÇÃO CIVIL PÚBLICA PARA TUTELADO MEIO AMBIENTE. OBRIGAÇÕES DE FAZER, DE NÃO FAZER E DE PAGAR QUANTIA. POSSIBILIDADE DE CUMULAÇÃO DE PEDIDOS ART. $3^{\circ}$ DA LEI 7.347/85. INTERPRETAÇÃO SISTEMÁTICA. CONDENAÇ̃̃O PARA RECOMPOR O DANO AMBIENTAL CAUSADO E AO PAGAMENTO DE UMA INDENIZAÇÃO PELOS DANOS ECOLÓGICOS . [...] 3. É possível a condenação cumulativa em obrigação de fazer ou não fazer e de pagar, sobretudo porque, em matéria ambiental, tal cumulação mostra-se ainda mais premente, em virtude do dano moral provocado à coletividade atingida pela devastação ecológica, tendo esse tipo de dano natureza peculiar, sendo de difícil reparação e mensuração, pelo que a condenação em dinheiro, se não consegue corresponder exatamente aos recursos naturais destruídos, no mínimo, desempenha um caráter educativo de intimidação à prática de ações similares. Portanto, a exegese dada pelo juízo é limitativa e não merece prevalecer, sob pena de se deturpar até mesmo o instituto da ação civil pública, que comporta não apenas condenação em prestações pessoais, positivas e negativas (fazer e não fazer), como também de pagar quantia, através de indenização dos danos insuscetíveis de recomposição "in natura". 4. A natureza do dano ambiental, porque diz respeito a um interesse difuso intangível, exige, além da reparação material - se possível de restituição à situação anterior - a reparação moral coletiva, porque não se atinge uma única esfera jurídica, mas um direito compartilhado transindividualmente por todos os cidadãos. Por isso é que é plenamente possível a condenação em indenização por dano moral coletivo, até porque existe previsão normativa expressa sobre a possibilidade de dano extrapatrimonial em relação a coletividades, consoante se depreende da parte final do artigo $1^{\circ}$ da Lei ${ }^{0}$ 7.347/85. [...]." (TRF5 - Segunda Turma, AC 431925/ CE, Desembargador Federal Francisco Barros Dias, DJe 15/09/2009). (Grifou-se)

"PROCESSUAL CIVILE EMBIENTAL. RESPONSABILIDADE CIVILE ADMINISTRATIVA. INDEPENDÊNCIA. RECOMPOSIÇÃO DO AMBIENTE E DANO MORAL COLETIVO. [....] 2. Comprovado o dano ambiental coletivo: (i) destruição de matacões, inclusive com uso de explosivos, e retirada de grande quantidade de areia da praia, para calçamento da propriedade particular; (ii) construção de muro à beira mar; (iii) realização de extenso aterro na área da praia; (iv) bloqueio de acesso do público à praia; $\mathrm{e}$ (v) manutenção de aves silvestres em cativeiro -, tudo em área de preservação permanente, inserida, outrossim, na Estação Ecológica de Tamoios, a responsabilidade civil é objetiva (art. $225, \S 3^{\circ}$, da CF e $14, \S 1^{\circ}$, da Lei n ${ }^{\circ} 6.938 / 81$ ), cabendo ampla reparação. 3. Deve o poluidor ser condenado, como ensina Guilherme Couto de Castro, simultaneamente na recomposição do ambiente, sob pena cominatória, e também em verba a título punitivo (A responsabilidade civil objetiva no direito brasileiro. $3^{\mathrm{a}}$ ed. Rio de Janeiro: Forense, 2000. p. 119-120), também chamada educativa, didática ou por dano moral coletivo, com base no $\operatorname{art}^{\circ} 1^{\circ}$ da Lei $n^{\circ}$

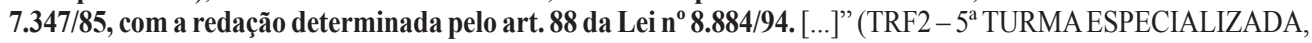
AC 292486, Desembargador Federal LUIZ PAULO S. ARAUJO FILHO, DJU 07/12/2009). (Grifou-se.)
} 
No seu voto-vencedor, esclareceu ainda o Min. TEORI ZAVASCKI:

O dano ambiental ou ecológico pode, em tese, acarretar também dano moral - como, por exemplo, na hipótese de destruição de árvore plantada por antepassado de determinado indivíduo, para quem a planta teria, por essa razão, grande valor afetivo.

Todavia, a vítima do dano moral é, necessariamente, uma pessoa. Não parece ser compatível com o dano moral a ideia da "transindividualidade" (= da indeterminabilidade do sujeito passivo e da indivisibilidade da ofensa e da reparação) da lesão. É que o dano moral envolve, necessariamente, dor, sentimento, lesão psíquica, afetando "a parte sensitiva do ser humano, como a intimidade, a vida privada, a honra e a imagem das pessoas" (Clayton Reis, Os Novos Rumos da Indenização do Dano Moral, Rio de Janeiro: Forense, 2002, p. 236), "tudo aquilo que molesta gravemente a alma humana, ferindolhe gravemente os valores fundamentais inerentes à sua personalidade ou reconhecidos pela sociedade em que está integrado" (Yussef Said Cahali, Dano Moral, $2^{a}$ ed., São Paulo: RT, 1998, p. 20, apud Clayton Reis, op. cit., p. 237).

Nesse sentido é a lição de Rui Stoco, em seu Tratado de Responsabilidade Civil, 6a ed., São Paulo: RT, que refuta a assertiva segundo a qual "sempre que houver um prejuízo ambiental objeto de comoção popular, com ofensa ao sentimento coletivo, estará presente o dano moral ambiental" (José Rubens Morato Leite, Dano Ambiental: do individual ao extrapatrimonial, $1^{\text {a }}$ ed., São Paulo: RT, 2000, p. 300, apud Rui Stoco, op. cit., p. 854):

"No que pertine ao tema central do estudo, o primeiro reparo que se impõe é no sentido de que não existe 'dano moral ao meio ambiente'. Muito menos ofensa moral aos mares, rios, à Mata Atlântica ou mesmo agressão moral a uma coletividade ou a um grupo de pessoas não identificadas.

A ofensa moral sempre se dirige à pessoa enquanto portadora de individualidade própria; de um vultus singular e único.

Os danos morais são ofensas aos direitos da personalidade, assim como o direito à imagem constitui um direito de personalidade, ou seja, àqueles direitos da pessoa sobre ela mesma.

$[\ldots]$

Ressuma claro que o dano moral é personalíssimo e somente visualiza a pessoa, enquanto detentora de características e atributos próprios e invioláveis.

Os danos morais dizem respeito ao foro íntimo do lesado, pois os bens morais são inerentes à pessoa, incapazes, por isso, de subsistir sozinhos. Seu patrimônio ideal é marcadamente individual, e seu campo de incidência, o mundo interior de cada um de nós, de modo que desaparece com o próprio indivíduo.

$[\ldots]$

De modo que, não sendo possível a recomposição imediata do dano causado ao meio ambiente, a condenação ao pagamento de multa e de um valor que seja suficiente para aquela futura restauração não exsurge como objetivo principal, mas apenas meio para alcançar a meta estabelecida pela Constituição da República.

$[\ldots]$ 
Do que se conclui mostrar-se impróprio, tanto no plano fático como sob o aspecto lógico-jurídico, falar em dano moral ao ambiente, sendo insustentável a tese de que a degradação do meio ambiente por ação do homem conduza, através da mesma ação judicial, à obrigação de reconstituí-lo, e, ainda, de recompor o dano moral hipoteticamente suportado por um número indeterminado de pessoas." (pp. 855-857)

Sucede que os fundamentos invocados para negar a possibilidade lógico-jurídica do dano moral coletivo em matéria ambiental não são sólidos.

Quanto ao primeiro argumento, é mister enfatizar que o dano moral não é indissociável dos sentimentos de dor, aflição, angústia psíquica, tanto que o próprio STJ editou a súmula no $227^{2}$, em que reconheceu, taxativamente, a possibilidade de pessoa jurídica fazer jus à percepção de indenização por dano moral, tendo em vista que as empresas, embora não possuam elas mesmas sentimentos de dor, aflição, humilhação, constrangimento, possuem uma "honra objetiva" (bom nome, reputação, conceito perante a sociedade etc.) merecedora de proteção jurídica. Por sua vez, os arts. 52 e 186 do CC/2002 dispõem:

Art. 52. Aplica-se às pessoas jurídicas, no que couber, a proteção dos direitos da personalidade.

Art. 186. Aquele que, por ação ou omissão voluntária, negligência ou imprudência, violar direito e causar dano a outrem, ainda que exclusivamente moral, comete ato ilícito.

No tocante ao segundo argumento, não há incompatibilidade lógicojurídica entre o dano moral e a indeterminação das vítimas, nem com a indivisibilidade da ofensa e da reparação.

De feito, esse problema é resolvido pelo art. 13 da Lei da ação civil pública (Lei 7.347/85), o qual determina que as condenações em dinheiro no bojo de ações civis públicas, incluidamente as de natureza ambiental, sejam destinadas a um fundo, cujos recursos serão destinados à reconstituição dos bens lesados:

Art. 13. Havendo condenação em dinheiro, a indenização pelo dano causado reverterá a um fundo gerido por um Conselho Federal ou por Conselhos Estaduais de que participarão necessariamente o Ministério Público e representantes da comunidade, sendo seus recursos destinados à reconstituição dos bens lesados."

2 Súmula 227 do STJ: “A pessoa JURÍDICA pode sofrer dano moral." 
Tal Fundo encontra-se regulamentado, no plano federal, pelo Decreto no 1.306/94. As condenações em dinheiro nas ações civis públicas ambientais devem reverter para esse Fundo ${ }^{3}$, mesmo após a criação do Fundo Nacional do Meio Ambiente, cujos recursos advêm de outras fontes ${ }^{4}$.

Destarte, se o valor da indenização pelo dano moral coletivo não será pago a pessoas específicas, mas destinado a um Fundo, não há por que exigir que as vítimas do dano moral coletivo sejam precisamente determinadas.

De seu turno, no que concerne aos direitos individuais homogêneos, os arts. 91 a 100 do Código de Defesa do Consumidor (CDC) $)^{5}$ preveem que a

3 Prescreve o Decreto no 1.306/94: “Art. $1^{\circ}$ O Fundo de Defesa de Direitos Difusos (FDD), criado pela Lei $\mathrm{n}^{\circ}$ 7.347, de 24 de julho de 1985, tem por finalidade a reparação dos danos causados AO MEIO AMBIENTE, ao consumidor, a bens e direitos de valor artístico, estético, histórico, turístico, paisagístico, por infração à ordem econômica e a outros interesses difusos e coletivos.

Art. $2^{\circ}$ Constituem recursos do FDD, o produto da arrecadação:

I - das condenações judiciais de que tratam os arts. 11 e 13, da Lei no 7.347, de 24 de julho de 1985; $[\ldots]$

III - dos valores destinados à União em virtude da aplicação da multa prevista no art. 57 e seu parágrafo único e do produto de indenização prevista no art. 100, parágrafo único, da Lei n ${ }^{\circ} 8.078$, de 11 de setembro de $1990 ;[\ldots]$

V - das multas referidas no art. 84, da Lei ${ }^{\circ} 8.884$, de 11 de junho de 1994;

VI - dos rendimentos auferidos com a aplicação dos recursos do Fundo;

VII - de outras receitas que vierem a ser destinadas ao Fundo;

VIII - de doações de pessoas físicas ou jurídicas, nacionais ou estrangeiras."

4 Dispõe a Lei 7.797/89: "Art. $1^{\circ}$ Fica instituído o Fundo Nacional do Meio Ambiente, com o objetivo de desenvolver os projetos que visem ao uso racional e sustentável de recursos naturais, incluindo a manutenção, melhoria ou recuperação da qualidade ambiental no sentido de elevar a qualidade de vida da população brasileira.

Art. $2^{\circ}$ Constituirão recursos do Fundo Nacional do Meio Ambiente de que trata o art. $1^{\circ}$ desta Lei:

I - dotações orçamentárias da União;

II - recursos resultantes de doações, contribuições em dinheiro, valores, bens móveis e imóveis, que venha a receber de pessoas físicas e jurídicas;

III - rendimentos de qualquer natureza, que venha a auferir como remuneração decorrente de aplicações do seu patrimônio;

IV - outros, destinados por lei."

5 “Art. 91. Os legitimados de que trata o art. 82 poderão propor, em nome próprio e no interesse das vítimas ou seus sucessores, ação civil coletiva de responsabilidade pelos danos individualmente sofridos, de acordo com o disposto nos artigos seguintes. (Redação dada pela Lei n ${ }^{\circ}$ 9.008, de 21.3.1995)

[...]

Art. 94. Proposta a ação, será publicado edital no órgão oficial, a fim de que os interessados possam intervir no processo como litisconsortes, sem prejuízo de ampla divulgação pelos meios de comunicação social por parte dos órgãos de defesa do consumidor.

Art. 95. Em caso de procedência do pedido, a CONDENAÇÃo SERÁ GENÉRICA, fixando a responsabilidade do réu pelos danos causados.

Art. 96. (Vetado).

Art. 97. A liquidação e a execução de sentença poderão ser promovidas pela vítima e seus sucessores, assim como pelos legitimados de que trata o art. 82 .

Parágrafo único. (Vetado).

Art. 98. A execução poderá ser coletiva, sendo promovida pelos legitimados de que trata o art. 82, abrangendo as vítimas cujas indenizações já tiveram sido fixadas em sentença de liquidação, sem prejuízo do ajuizamento de outras execuções. (Redação dada pela Lei no 9.008, de 21.3.1995) - (Cont. pág. 65) 
condenação fixada na sentença da ação civil pública pode ser genérica, em ordem a possibilitar a sua ulterior liquidação e execução por consumidores, em caráter individual, e, em caso de inércia destes por prazo superior a um ano, possibilitar sua execução pelas entidades previstas no art. 82 do CDC, hipótese em que o valor da condenação também reverterá para o fundo a que alude o art. 13 da Lei 7.347/85 (LACP). Tais normas inspiram-se no sistema de fluid recovery ("reparação fluida") do direito norte-americano.

ADA PELEGRINI (2001, p. 822-823) explana:

As ações coletivas que têm por objeto a reparação dos danos causados a pessoas indeterminadas podem carrear consigo algumas dificuldades. É o que tem demonstrado a experiência norte-americana, quando a sentença condena o réu a ressarcir o dano causado a centenas ou milhares de membros da class, surgindo então problemas de identificação das referidas pessoas; de distribuição entre elas da arrecadação; do uso do eventual resíduo não reclamado pelos membros da coletividade.

A jurisprudência norte-americana criou então o remédio da fluid recovery (uma reparação fluida), a ser eventualmente utilizado para fins diversos dos ressarcitórios, mas conexos com os interesses da coletividade: por exemplo, para fins gerais de tutela dos consumidores OU DO AMBIENTE.

[...] No sistema criado pelo Código, o bem jurídico objeto de tutela ainda é indivisível e a condenação é genérica, limitando-se a fixar a responsabilidade do réu e a reparar os danos causados. Estes serão apurados e quantificados em liquidação de sentença, movida por cada uma das vítimas para a posterior execução e recebimento da importância correspondente à sua reparação.

Portanto, o argumento de que o dano moral é, por natureza, incompatível com a indeterminabilidade das vítimas, e com a indivisibilidade da ofensa e da reparação, não resiste a uma análise da própria legislação que rege a matéria.

$\S 1^{\circ}$ A execução coletiva far-se-á com base em certidão das sentenças de liquidação, da qual deverá constar a ocorrência ou não do trânsito em julgado.

$\S 2^{\circ}$ É competente para a execução o juízo:

I - da liquidação da sentença ou da ação condenatória, no caso de execução individual;

II - da ação condenatória, quando coletiva a execução.

Art. 99. Em caso de concurso de créditos decorrentes de condenação prevista na Lei n. ${ }^{\circ}$ 7.347, de 24 de julho de 1985 e de indenizações pelos prejuízos individuais resultantes do mesmo evento danoso, estas terão preferência no pagamento.

Parágrafo único. Para efeito do disposto neste artigo, a destinação da importância recolhida ao fundo criado pela Lei n ${ }^{\circ} .347$ de 24 de julho de 1985, ficará sustada enquanto pendentes de decisão de segundo grau as ações de indenização pelos danos individuais, salvo na hipótese de o patrimônio do devedor ser manifestamente suficiente para responder pela integralidade das dívidas.

Art. 100. Decorrido o prazo de um ano sem habilitação de interessados em número compatível com a gravidade do dano, poderão os legitimados do art. 82 promover a liquidação e execução da indenização devida.

Parágrafo único. O produto da indenização devida reverterá para o fundo criado pela Lei $n .^{\circ}$ 7.347, de 24 de julho de 1985." 
De mais a mais, este argumento, em última análise, conflita com o primeiro. Com efeito, o primeiro argumento parte da premissa de que a coletividade não é uma pessoa física, sendo, portanto, incapaz de sofrer abalo psíquico ensejador de dano moral. Já o segundo argumento parte de premissa diversa: de que os sujeitos passivos (= vítimas) do dano moral seriam pessoas indeterminadas e indetermináveis, sendo, por conseguinte, indivisíveis a ofensa e a reparação. Assim, conforme o segundo argumento, a vítima do dano moral não seria a coletividade (como se supõe no primeiro argumento), mas as pessoas físicas (indetermináveis) que a compõem.

Como a "coletividade" não ostenta personalidade jurídica distinta de seus membros (à diferença do que ocorre com as empresas em relação aos seus sócios), qualquer ofensa moral que lhe seja infligida será infligida a cada qual de seus componentes ${ }^{6}$. Assim, uma ofensa irrogada a um grupo religioso será uma ofensa sentida por cada qual de seus integrantes, e não apenas pelo "grupo" enquanto tal".

Releva observar que o art. $1^{\circ}$ da Lei $7.347 / 85$ foi alterado pela Lei 8.884/94 justamente para prever expressamente a viabilidade de condenação em danos morais em ações civis públicas, inclusivamente as ambientais. A intentio legis parece clara: possibilitar condenação por dano moral coletivo.

Uma vez que as condenações em dinheiro em ações civis públicas devem reverter para o Fundo previsto no art. 13 da LACP (Lei 7.347/85), não é razoável supor que intentio legis tenha sido possibilitar uma desnecessária condenação por danos morais individuais em sede de ação civil pública (coletiva), por meio de restritos legitimados, quando já havia a possibilidade de ajuizamento de ações individuais de ressarcimento de dano moral (individual), cujo valor seria pago diretamente ao ofendido autor da ação, e não ao Fundo mencionado no art. 13 da LACP. Confira-se a redação do referido art. $1^{\mathrm{o}}$ :

Art. $1^{\circ}$ Regem-se pelas disposições desta Lei, sem prejuízo da ação popular, as ações de responsabilidade POR DANOS MORAIS e patrimoniais causados: (Redação dada pela Lei n ${ }^{\circ} 8.884$, de 11.6.1994)

I - ao meio-ambiente ${ }^{8}$;

II - ao consumidor;

III - à ordem urbanística; (Incluído pela Lei n ${ }^{\circ}$ 10.257, de 10.7.2001) (Vide Medida provisória $\mathrm{n}^{\mathrm{O}} 2.180-35$, de 2001)

IV - a bens e direitos de valor artístico, estético, histórico, turístico e paisagístico; (Renumerado do Inciso III, pela Lei $\mathrm{n}^{\circ} 10.257$, de 10.7.2001)

\footnotetext{
${ }^{6}$ Mas o inverso não é verdade: nem toda ofensa sentida por um membro de um grupo (ofensa individual) atinge o grupo todo.

7 Questão diversa é saber se é possível cumular condenação por danos morais coletivos com condenação por danos morais individuais. Édis Milaré (2005, p. 177-179) defende que é possível, estremando as duas espécies de dano: "(i) o dano ambiental coletivo ou o dano ambiental propriamente dito, causado ao meio ambiente globalmente considerado, em sua concepção difusa, como patrimônio coletivo; e (ii) o dano ambiental individual, que atinge pessoas, individualmente consideradas, através de sua integridade moral e/ou de seu patrimônio material particular."

8 Eis a redação original do art. 1o da LACP, antes da alteração promovida pela Lei no 8.884/94: “Art. $1^{\circ}$ Regem-se pelas disposições desta Lei, sem prejuízo da ação popular, as ações de responsabilidade por danos causados: I - ao meio-ambiente; [...]"
} 
V - por infração da ordem econômica e da economia popular; (Redação dada pela Medida provisória $\mathrm{n}^{\circ} 2.180-35$, de 2001)

VI - à ordem urbanística. (Redação dada pela Medida provisória nº 2.18035, de 2001)

Parágrafo único. Não será cabível ação civil pública para veicular pretensões que envolvam tributos, contribuições previdenciárias, o Fundo de Garantia do Tempo de Serviço - FGTS ou outros fundos de natureza institucional cujos beneficiários podem ser individualmente determinados. (Incluído pela Medida provisória $\mathrm{n}^{\mathrm{0}} 2.180-35$, de 2001)

De qualquer sorte, há sinalização de que a jurisprudência do STJ ainda não está solidificada no sentido do julgamento do REsp 598.281. De fato, neste mesmo REsp 598.281 (1a Turma do STJ) houve notáveis votos vencidos, como do Min. José Delgado e do Min. Luiz Fux (relator originário), sendo de ressaltar ainda o voto da Min. Denise Arruda, segundo o qual é possível a condenação em danos morais coletivos, desde que haja "evidência de violação do sentimento coletivo da comunidade local", que não reputou verificada na espécie ${ }^{9}$.

Ademais, no julgamento do REsp 636.021/RJ pela $3^{\text {a }}$ Turma do STJ, a Min. Nancy Andrighi, em erudito voto vencido, discordou expressamente dos fundamentos adotados no REsp 598.281/MG. Todavia, a matéria de fundo não chegou a ser julgada por razões de ordem processual ${ }^{10}$, razão pela qual ainda não há entendimento firmado pela $3^{\mathrm{a}}$ Turma do STJ.

9 Todavia, ao menos por ora, no âmbito da 1a Turma do STJ tem prevalecido o entendimento sufragado no REsp 598.281, porquanto este precedente foi invocado no julgamento do REsp 971.844/RS, também da Relatoria do Min. Teori Zavascki, cuja ementa é a seguinte: "PROCESSUAL CIVIL E ADMINISTRATIVO. CONCESSIONÁRIA DE SERVIÇO DE TELEFONIA. POSTOS DE ATENDIMENTO. INSTALAÇÃO. AUSÊNCIA DE PREVISÃO NO CONTRATO DE CONCESSÃO. DISCRICIONARIEDADE DA ADMINISTRAÇÃO PÚBLICA. FUNDAMENTOS INATACADOS. SÚMULA 283/STF. MATÉRIA FÁTICA. SÚMULA 07/STJ. DANO MORAL COLETIVO. EXISTÊNCIA NEGADA. SÚMULA 07/ STJ. ACÓRDÃO COMPATÍVEL COM PRECEDENTES DA 1ª TURMA. RESP 598.281/MG, MIN. TEORI ALBINO ZAVASCKI. DJ DE 01.06.2006; RESP 821891, MIN. LUIZ FUX, DJ DE 12/05/08, RECURSO ESPECIAL PARCIALMENTE CONHECIDO E, NESTA PARTE, DESPROVIDO.”

(REsp 971.844/RS, Rel. Ministro TEORI ALBINO ZAVASCKI, PRIMEIRA TURMA, julgado em 03/12/2009, DJe 12/02/2010)

${ }^{10}$ Eis o teor da ementa: "AÇ̃̃O CIVIL PÚBLICA - AJUIZAMENTO PELO MINISTÉRIO PÚBLICO - REPRISE DE NOVELA EM HORÁRIO VESPERTINO - ALEGAÇÃO DE NÃO SUPRESSÃO SUFICIENTE DE CENAS DE SEXO E VIOLÊNCIA - REJEIÇÃO DE REQUERIMENTO DE REALIZAÇÃO DE PROVA SOB O FUNDAMENTO DE QUE MATÉRIA PREJUDICADA INDEFERIMENTO DE PROVAPERICIAL - ALEGAÇÃO DE NECESSIDADE NÃO APRECIADA PELO TRIBUNAL DE ORIGEM - RECURSO ESPECIAL PROVIDO - ANULAÇÃO DO JULGAMENTO DOS EMBARGOS DE DECLARAÇÃO.

Acolhida a alegação de que não apreciada pelos Embargos de Declaração a alegação de que havia necessidade de realização de prova pericial nos termos em que requerida, anula-se o Acórdão dos Embargos de Declaração, para que outro Acórdão seja proferido pelo Tribunal de Origem, permanecendo as demais matérias preliminares e de fundo por ora sem julgamento - Prevalência dos votos dos Min. HUMBERTO GOMES DE BARROS E ARI PARGENDLER, nos termos do voto deste último, seguido pelo voto do Min. SIDNEI BENETI, vencida a Min. NANCY ANDRIGHI, que não conhecia do Recurso Especial. Recurso especial provido.” (REsp 636.021/RJ, Rel. Ministra NANCY ANDRIGHI, Rel. p/ Acórdão Ministro SIDNEI BENETI, TERCEIRA TURMA, julgado em 02/10/2008, DJe 06/03/2009.) 
Por fim, impende afastar a ideia de que a condenação por dano moral coletivo corresponderia à aplicação de uma "multa (sanção) sem previsão legal"11. Com efeito, é pacífico na doutrina e na jurisprudência que a condenação por dano moral individual possui dúplice natureza: ressarcitória (indenizatória propriamente dita) + pedagógico-punitiva (visante a desestimular o ofensor a reincidir na conduta danosa). Na condenação por dano moral coletivo, dá-se o mesmo, conquanto se verifique que o caráter punitivo-pedagógico assume maior relevo que o ressarcitório ${ }^{12}$.

Ademais, o valor das condenações por dano moral individual não costuma, via de regra, ser previsto em lei, competindo ao julgador fixar o montante da condenação em patamar razoável e proporcional, de modo que a condenação não seja tão ínfima a ponto de desestimular a reiteração da conduta, nem tão elevada a pique de gerar enriquecimento indevido para o ofendido. Portanto, basta a previsão constitucional de que o dano moral seja indenizado para que seja possível condenação judicial por dano moral individual.

Identicamente, na hipótese de dano moral coletivo, não há por que exigir que o seu montante seja previamente fixado em lei, cabendo ao julgador fixá-lo atendendo às peculiaridades do caso concreto, observando os princípios constitucionais da proporcionalidade e da razoabilidade. Destarte, basta a previsão constitucional e legal (Lei 7.347/85, art. $1^{\circ}$ ) de que o dano moral seja indenizado para possibilitar condenação judicial por dano moral coletivo.

${ }^{11}$ Argumento defendido pelo eminente Min. Humberto Gomes de Barros no julgamento do REsp 636.021/RJ.

${ }^{12}$ De fato, a condenação por dano moral coletivo revela-se mais necessária naqueles casos em que os membros do grupo não se animariam a propor ações individuais de indenização por dano moral (seja pelo reduzido valor médio dessas condenações, seja pelo gigantismo do ofensor e da hipossuficiência dos ofendidos, seja por qualquer outro motivo), mas a ofensa moral à coletividade é bastante considerável. Nesse sentido: “AÇÃO CIVIL PÚBLICA. PRELIMINAR - CERCEAMENTO DE DEFESA. AFASTAMENTO. FECHAMENTO DOS POSTOS DE ATENDIMENTO PESSOAL. SUBSTITUIÇÃO PELO SERVIÇO DE 'CALL CENTER'. ILEGALIDADE DO PROCEDIMENTO. OBRIGATORIEDADE DAMANUTENÇÃO DE LOJAS. DELIMITAÇÃO DA CONDENAÇÃO. DIREITO DE INFORMAÇÃO DO USUÁRIO. ART. $7^{\circ}$, LEI No 8.987/95 E ART. $3^{\circ}$, LEI No 9.472/97. DANOS MORAIS COLETIVOS. - [...] A ocorrência de danos morais coletivos é matéria relativamente nova na jurisprudência. Doutrinariamente, o dano moral é conceituado como o prejuízo de caráter intrínseco ao íntimo do ofendido, isto é, ligado à esfera da personalidade. A coletividade, por óbvio, é desprovida desse conteúdo próprio da personalidade. Entretanto, não pode permanecer desamparada diante de atos que atentam aos princípios éticos da sociedade. - Costuma-se dizer que o dano moral tem dupla função: reparar o dano sofrido pela vítima e punir o ofensor. O denominado "dano moral coletivo" busca, justamente, valorar a segunda vertente, mas sob um prisma diferente. Mais do que punir o ofensor, confere um caráter de exemplaridade para a sociedade, de acordo com a importância que o princípio da moralidade administrativa adotou hodiernamente. - Dessa forma, o dano moral coletivo tem lugar nas hipóteses onde exista um ato ilícito que, tomado individualmente, tem pouca relevância para cada pessoa; mas, frente à coletividade, assume proporções que afrontam o senso comum. [...]" (TRF 4 - 3a Turma, AC 200270020031645, Rel.: VÂNIA HACK DE ALMEIDA, DJ 27/09/2006). Na mesma linha: AC 200371010019370, Rel.: VÂNIA HACK DE ALMEIDA, DJ 30/08/2006. 


\section{Conclusões}

1. O dano moral não é indissociável dos sentimentos de dor, aflição, angústia psíquica, tanto que o próprio STJ editou a súmula no 227, em que reconheceu, taxativamente, a possibilidade de pessoa jurídica fazer jus à percepção de indenização por dano moral, tendo em vista que as empresas, embora não possuam elas mesmas sentimentos de dor, aflição, humilhação, constrangimento, possuem uma "honra objetiva" (bom nome, reputação, conceito perante a sociedade etc.) merecedora de proteção jurídica.

2. Não há incompatibilidade lógico-jurídica entre o dano moral e a indeterminação das vítimas, nem com a indivisibilidade da ofensa e da reparação. De fato, esse problema é resolvido pelo art. 13 da Lei da ação civil pública (Lei 7.347/85), o qual determina que as condenações em dinheiro no bojo de ações civis públicas, incluidamente as de natureza ambiental, sejam destinadas a um fundo, cujos recursos serão destinados à reconstituição dos bens lesados.

Dessarte, se o valor da indenização pelo dano moral coletivo não será pago a pessoas específicas, mas destinado a um Fundo, não há por que exigir que as vítimas do dano moral coletivo sejam precisamente determinadas.

3. $\mathrm{O}$ art. $1^{\circ}$ da Lei $7.347 / 85$ foi alterado pela Lei no 8.884/94 justamente para prever expressamente a viabilidade de condenação em danos morais em ações civis públicas, inclusivamente as ambientais. A intentio legis parece clara: possibilitar condenação por dano moral coletivo.

4. A possibilidade de condenação por dano moral coletivo em ação civil pública, especialmente em matéria ambiental, representa uma inegável conquista da cidadania e um dos meios mais eficazes para prevenir danos ambientais. Espera-se, pois, que o STJ, que se tem revelado um verdadeiro "Tribunal da Cidadania", assegure o seu cumprimento.

\section{REFERÊNCIAS}

GRINOVER, Ada Pelegrini et al. Código brasileiro de defesa do Consumidor: comentado pelos autores do anteprojeto. 7. ed. Rio de Janeiro: Forense Universitária, 2001.

MILARÉ, Édis. Direito do Ambiente. São Paulo: RT, 2005.

COLLECTIVE MORAL DAMAGES DUE TO ENVIRONMENTAL VIOLATION

Abstract: There is a growing perception that the environment must be as protected as possible: the global warming, for instance, is a 
reality increasingly harder to ignore. One of the most effective means to prevent environmental damages is the judicial condemnation for collective moral damage. Nevertheless, even though the existence of collective moral damage may be undisputedly accepted by doctrine and by Brazilian federal courts, a more restrictive understanding of the Superior Tribunal of Justice (STJ), currently prevalent, denies the very possibility of collective moral damage, under the argument that such concept is incompatible with the idea of psychological pain, with the indetermination of the victim and with the indivisibility of the offense and reparation. On the contrary, in this article it is sustained the perfect consistency of the collective moral damage with the Brazilian legal system.

Keywords: Collective moral damage. Environmental damages. Transindividual rights. Collective actions.

Data de recebimento: set/2010 - Data de aprovação: nov/2010 